\title{
Por uma teoria psicossocial: os elos perdidos em G. H. Mead
}

\author{
For a Psychosocial Theory: the missing links in G. H. Mead
}

Antônio Augusto Oliveira Gonçalves ${ }^{1}$, Eliane Schmaltz Ferreira ${ }^{2}$

\begin{abstract}
Resumo
A incursão proposta neste artigo trilha o caminho inverso da compartimentação disciplinar, no âmbito da ciência e da filosofia, buscando assim ultrapassar algumas comodidades analíticas. O objeto de estudo em questão é a teoria psicossocial de George Herbert Mead, um filósofo e psicólogo social norte-americano que viveu de 1863 a 1931. Partimos de um estado da arte, uma metodologia de caráter inventariante e descritiva. Da leitura e da interpretação do levantamento bibliográfico, que incluía desde artigos redigidos por Mead até textos clássicos de epistemologia. Foi possível estabelecer dois movimentos inversos, mas complementares, num duplo esforço apreciativo paradoxalmente centrífugo e centrípeto. Colocamos em evidência preceitos de cadência histórica, vasculhamos aquilo que estava além da psicologia social de Mead - os antecedentes filosóficos e o plano das relações interpessoais e científicas de seu tempo. A interlocução entre as considerações biográficas de Mead e o desenvolvimento histórico da psicologia social permitiu compreender as raízes do pensamento meadiano e os seus desdobramentos ulteriores.
\end{abstract}

Palavras-chave: História da Ciência. George Herbert Mead. Psicologia social.

\begin{abstract}
The incursion proposed in this article trail the opposite way of the disciplinary compartmentalization in the scope of science and philosophy, seeking to overcome some analytical commodities. The object of study in question is the psychosocial theory of George Herbert Mead, a North American philosopher and social psychologist who lived between 1863-1931. We start with a state of the art, a methodology of executrix character and descriptive. From the reading and the interpretation of bibliographical survey, from articles written by Mead to classic texts of epistemology, it was possible to establish two inverse but complementary movements in a dual appreciative effort paradoxically centrifugal and centripetal. We put in evidence precepts of historical cadence; we rummaged what was beyond social psychology of Mead, the philosophical background and the interpersonal relations and scientific plan of his time. The interlocution among the biographical considerations of Mead and historical development of social psychology allowed to understand the roots of Meadian thought and its further unfolding.
\end{abstract}

Keywords: History of Science. George Herbert Mead. Social Psychology.

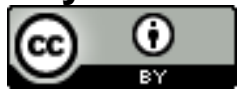

Esta obra foi licenciada com uma Licença Creative Commons - Atribuição 3.0 Não Adaptada.

\footnotetext{
${ }^{1}$ Instituto de Ciênciais Sociais, Universidade Federal de Uberlândia. E-mail: antonioaugusto.sociais@hotmail.com

${ }^{2}$ Instituto de Ciências da Universidade Federal de Uberlândia. Docente do Programa de Pós-Graduação em Ciências Sociais - UFU. E-mail: esferreira@ufu.br

Cad. de Pesq. Interdisc. em Ci-s. Hum-s. Florianópolis, Santa Catarina, Brasil, ISSN 1984-8951
} v.14, n.105, p.19-49 ago/dez 2013 


\section{Introdução}

Respaldado por um levantamento bibliográfico correspondente ao limiar de alcance da análise, este artigo, na sua projeção de pesquisa, pressupõe o seguinte rascunho epistêmico: um estado da arte da psicologia social de George Herbert Mead, poder-se-ia então, partir de um exame rico em evidências das raízes europeias, sobretudo, as filiações ao idealismo alemão, as linhas de influência de Dilthey, Charles Darwin e Albert Einstein. Por conseguinte, assim que tivéssemos munidos das estirpes do pensamento meadiano, a tarefa de percepção da morfologia e fecundidade da flor americana, na Universidade de Chicago, em 1900, tornar-se-ia mais consistente e menos dispendiosa, segundo os critérios de economia de explicação aludidos por $\mathrm{Eco}^{3}$ (1996). O processo da analepse exegética, portanto, prevê uma dimensão de investigação que revisita os contextos intelectuais de contato entre Mead e outros teóricos, tal como Wilhelm Wundt, Ebbinghaus e Cooley, a ponto de identificar, em termos acertados, os pilares filosóficos e científicos do arcabouço meadiano. Nessa perspectiva, Morris (1934, p. IX) consegue deslindar a escola de pensamento a que pertence G. H. Mead:

Filosoficamente falando, Mead era um pragmático; cientificamente falando, ele era um psicólogo social. Pertencia a uma antiga tradição - a tradição de Aristóteles, Descartes, Leibniz; de Russel, Whitehead, Dewey - que não consegue ver nenhuma separação essencial, ou nenhum antagonismo, entre as atividades da ciência e da filosofia, e cujos membros são, eles próprios, cientistas e filósofos ao mesmo tempo.

Por isso, Farr (1996) salienta que a chave para compreensão do sistema em filosofia de Mead está na sua psicologia social, ao passo que a clavis da teoria

\footnotetext{
${ }^{3}$ A maior economia possível na explicação é um critério de Eco no qual diferencia a interpretação sã de espírito da interpretação paranóica. Para ilustrar, utilizemos um exemplo pormenorizado pelo próprio Eco. No Renascimento, constatou-se uma analogia morfológica entre a orquídea com dois bolbos esferóides e os testículos. Bacon (1620 apud ECO, 1993) esmiúça que a orquídea possui dois bolbos porque durante todos os anos se forma um bolbo nupérrimo que medra ao lado do antigo, e, enquanto, aquele desenvolve, este murcha. Logo, nota-se alguma diferença no que tange ao processo de fertilização entre os bolbos e os testículos, assim, a analogia formal estremece face a incapacidade inerente de transpor o fenômeno morfológico para o âmbito das relações de causa e efeito. Desse modo, o pensamento hermenêutico apoia-se na semelhança morfológica que não se segue nos dados atinentes a atividade sexual, no caso dos testículos. Logo, a explicação auferida do cotejamento entre os elementos é pouco compensatória e não satisfaz o critério de economia de explicação, devido ao fato de se apoiar numa interpretação paranóica. Para maiores detalhes, vide: ECO, Umberto. Sobreinterpretação de Textos. In: COLLINI, Stefan. Interpretação e Sobreinterpretação. Lisboa: Editorial Presença, 1993. p. 45-61.
}

Cad. de Pesq. Interdisc. em Ci-s. Hum-s. Florianópolis, Santa Catarina, Brasil, ISSN 1984-8951 v.14, n.105, p.19-49 ago/dez 2013 
psicossocial meadiana encontra-se no seu terreno filosófico. Mead por meio de seu Curso Anual de Psicologia Social, ${ }^{4}$ na Universidade de Chicago, desenvolveu o seu próprio sistema em filosofia. Quaisquer interpretações que se apeguem apenas no horizonte filosófico e dirima a perspectiva em ciência, e vice-versa, revela-se incipiente no exercício interpretativo, e promove, inexoravelmente, um esvaziamento na compreensão da complexidade constituída nesse edifício interdisciplinar. O problema fulcral é que tantos os filósofos quanto os sociólogos e psicólogos, em larga medida, leem somente a sua literatura corrente, ou seja, específica do campo científico o qual estão vinculados. Com isso, negligenciam a dos outros especialistas e dessa maneira não conseguem ter a percepção de como elas estão imbricadas entre si.

A separação acadêmica em disciplinas dentro da Universidade de Chicago já havia sido principiada no começo do século XX e estava praticamente concluída na época da morte de Mead, em 1931. Sobre esse aspecto nos reservamos a pormenorizá-lo adiante, nas seções "O Efeito Redoma e o Descaso Histórico" e "G. H. Mead: considerações biográficas e a sua carreira", por duas ordens de motivo. Primeiro, porque o prospecto detém algum pendor positivista, representando uma reverberação no quadro das relações interpessoais de Mead e, mais ainda, nas relações institucionais entre filósofos e psicólogos. Segundo, os últimos, na busca de uma ciência experimental, não quiseram olhar para o passado metafísico da disciplina. Por conseguinte, os sociólogos - sobretudo os estudantes de pósgraduação em sociologia -, através de veementes recomendações de Allbion Small e Faris, passaram a frequentar o curso de Mead, no Departamento de Filosofia (LEWIS; SMITH, 1980). Ao debruçar-se sobre tais fatores, necessitamos aceitar as diligências que a empresa acarreta, isto é, cruzar os paradigmas filosóficos e a história da psicologia com a vida e trajetória acadêmica de Mead. Por agora, parecenos fecundo esclarecer certos preceitos de cadência histórica, quer da história das ideias, quer da história das instituições, no que se refere à emergência da psicologia social nos Estados Unidos e as raízes europeias do fenômeno.

\footnotetext{
${ }^{4}$ Para Farr (1996), tal curso foi ofertado pela primeira vez 1900 e continuou até a data da morte de Mead em 1931. Morris (2010) é mais preciso na calendarização porque afirma que 1930 é o último ano em que o curso foi ministrado de forma integral. Miller (1973) ratifica, em algum sentido, a demarcação temporal de Morris, porque frisa que John Dewey esteve com Mead durante essa última enfermidade e ofereceu-lhe um cargo na Universidade de Columbia para o outono de 1931, contudo Mead faleceu antes que pudesse assumir esse posto.
}

Cad. de Pesq. Interdisc. em Ci-s. Hum-s. Florianópolis, Santa Catarina, Brasil, ISSN 1984-8951 v.14, n.105, p.19-49 ago/dez 2013 
As ciências humanas e sociais, pertencentes a uma tradição intelectual ocidental, nomeadamente aquelas de proveniência europeia, afiguram-se enquanto as raízes da psicologia social (JAHODA, 1992, SMITH, 1997, FARR, 2007). Nesse sentido, Allport (1954) alarga o período para antes da filosofia comteana e remonta as estirpes na ciência política, nos fundamentos teóricos acerca do liame entre a natureza propriamente humana e o estado e a resolução que se dá ao nível do contrato social. Não é por acaso que Allport dedica-se a análise e exposição do clássico hobessiano, o Leviatã, inclusive replicou o frontispício do livro. A incursão de Allport em torno do alhures germinal não ultrapassa a mera especulação, ou seja, a fase metafísica da evolução da disciplina. A fase posterior, a positiva, apresenta-se naquele que é considerado o fundador da psicologia social, ainda no ponto de vista de Allport, Comte. Por certo, essa escolha do autor canônico ecoa no próprio projeto concretizado para a psicologia social, convertida assim numa ciência social moderna (FARR, 2007). Samelson (1974), num ataque desfechado a Allport, entende o falso mito de origem como interpretação "whig" ${ }^{5}$ da história da psicologia social. Por outras palavras, Allport, fortemente inspirado por um espírito da filosofia positivista da ciência, constrói uma história dos vencedores, na qual a lente comteana do presente reflete-se na procura do passado metafísico em Hobbes e na hodierna maturidade científica em Comte.

Consoante a Samelson, Farr (2007) é reticente quanto às origens apontadas por Allport e remete para uma tradição nascente em meados do século XIX, no sistema universitário alemão, denominada Wissenschaft, que desemboca no surgimento da universidade moderna. Institucionalizou-se, dessa maneira, um divisor de águas entre a forma medieval de universidade e a moderna. A base de rolamento é, precisamente, uma controvérsia entre as Naturwissenschaften (as ciências naturais) e Geisteswissenschaften (ciências humanas e sociais), são formas rivais de Wissenschaft. A tradução para o termo Wissenschaft equivale aproximadamente à ciência, porém Farr (1996) é prudente quanto ao uso dessa

\footnotetext{
${ }^{5}$ Refere-se ao processo de reconstrução do passado pelo ponto de vista do presente. O que leva, inexoravelmente, que nossa ressignificação do passado perpassa pelo crivo de nossos interesses do presente. Tal desvio acarreta o que alguns historiadores designam por "presentismo", do qual a lógica de interpretação dos eventos equivale a sobrevivência no devir histórico, daquilo que foi bemsucedido e, portanto, protela-se até o status quo. Cf. em: BUTTERFIELD, H. The Whig Interpretation of History. Londres: Bell, 1951.
} 
terminologia, e sua correspondente significação não pode ser estendida para todo continente europeu, uma vez que, no País de Gales e na Inglaterra, a sua utilização tem um emprego muito restrito, fazendo menção somente às ciências naturais. Nesse sentido, a distinção categórica assinalada nas universidades alemãs torna-se importante, pois foi um acicate que levou Wilhelm Wundt a desprender sua psicologia experimental, enquanto parte das Naturwissenschaften, de sua psicologia social, integrante das Geisteswissenschaften. Assim, Wundt assume que a psicologia era apenas parte das ciências humanas, carecendo ser suplementada por um ramo das ciências naturais. Como corolário, Wundt pleiteia que não é possível estudar fenômenos como o pensamento e os processos mentais superiores através da introspecção. ${ }^{6}$ Era um desdobramento de cunho epistemológico, a mente não pode rodar sobre os calcanhares, voltando para si mesma e perscrutar os conteúdos de que ela mesma é produto. Desse modo, Wundt, nos volumes da Völkerpsychologie, estabelece uma separação entre os processos generativos dos fenômenos mentais coletivos e aqueles dados atinentes à psicologia fisiológica (ARAÚJO, 2009).

Ainda na Europa, outro expoente trilhou o mesmo desígnio, só que do âmbito de uma disciplina distinta: a sociologia. Na França, Émile Durkheim efetivamente transformou a sociologia numa ciência autônoma, desvinculada da psicologia, distinguindo os eventos coletivos dos individuais e defendendo que deveriam ser tratados independentemente. Ele o fez no livro "As Regras do Método Sociológico" (1976), ao alegar que o objeto próprio da sociologia é o fato social e um fato social só pode ser explicado em função de outro, nunca por referência a valência individual. Em "O Suicídio", Durkheim (1982) refutou as teses atomistas que cercavam o tema, demonstrando que o suicídio, longe de ser um ato puramente individual, é antes efeito do meio social, no qual o agente se insere. O que poucos sabem é que há menos de uma década antes da publicação de "Da Divisão Social do Trabalho", em 1893 (DURKHEIM, 1977), Durkheim havia visitado diversas universidades alemãs entre 1885 e 1886, dentre elas a Universidade de Leipzig, onde funcionava o laboratório experimental de Wundt. O sociólogo francês manifestou apreço pela exatidão, os dotes organizacionais e a fundação de um

\footnotetext{
${ }^{6}$ Para Wundt, a psicologia fisiológica tem dois enfoques no indivíduo, um a partir dentro, o da psicologia e outro para fora, o da fisiologia. O recurso metodológico wundtiano, a introspecção, é conceituado por Araújo (2009) como a forma de percepção interna.

Cad. de Pesq. Interdisc. em Ci-s. Hum-s. Florianópolis, Santa Catarina, Brasil, ISSN 1984-8951
} v.14, n.105, p.19-49 ago/dez 2013 
Instituto e uma revista, um extenso legado deixado por Wundt. Logo, tanto Durkheim na França quanto Wundt na Alemanha são figuras idôneas, o primeiro pela sua distinção radical entre psicologia e sociologia, o segundo em virtude da tradição Wissenschaft. Ambos os teóricos eram antirreducionistas, e isso tem uma implicância no desenvolvimento histórico da psicologia social. Esta surge enquanto uma disciplina-charneira, mas, também, como um subdomínio da sociologia e da psicologia (FARR, 1996).

\section{Da análise documental}

Para o sociólogo Weber (2003), a realidade é infinita e apresenta múltiplas possibilidades. Segundo o autor, é impossível um estudo que consiga haurir a finitude da realidade social. Para tanto, é fundamental o recorte do objeto de estudo, transformando o aspecto incomensurável da realidade em uma parte finita. $O$ pesquisador, por meio da relação com os valores, na terminologia weberiana, seleciona o objeto de análise científica. Assim, o recorte dessa pesquisa é a teoria psicossocial de Mead. Tal como supracitado por Morris (1934), Mead não esteve estritamente ligado a um campo disciplinar específico, mas, antes, as trilhas do seu pensamento perpassam desde a antítese de Wundt - o problema da consciência individual e a mente em relação a sociedade - até o conceito de perspectiva, derivado de Einstein. Para tanto, a pesquisa se pauta numa abordagem incursiva, visando uma aproximação em torno das estirpes filosóficas e científicas do pensamento meadiano. Além disso, esse estudo foi respaldado, metodologicamente, por um mapeamento e discussão das ideias e formulações conceituais de Mead trata-se de um estado da arte, uma metodologia de caráter inventariante e descritiva (MATOS, 2008). O procedimento de coleta de dados, por sua vez, é a pesquisa documental. Para Cellard (2008), a análise documental se baseia em cinco (5) critérios básicos:

- o contexto é o exame do "contexto social global" em que o documento ou texto foi elaborado. Essa análise permite compreender a conjuntura social, cultural, política e econômica que resultou na produção do documento, além de identificar locais, personagens e grupos sociais específicos que o texto faz alusão; 
- o autor é a análise da identidade da pessoa que escreveu o documento, um diagnóstico detalhado de seus interesses e motivos que a levaram a confeccionar tal texto;

- a autenticidade e a confiabilidade do texto referem-se à necessidade de garantir a qualidade da informação transmitida;

- a natureza do texto é um critério dirigido à diversidade da natureza das composições textuais. Os documentos de natureza sociológica, teológica ou histórica são formulados e estruturados de formas diferentes "e só adquirem um sentido para o leitor, em função de seu grau de iniciação no contexto particular de sua produção" (CELLARD, 2008, p. 302); e

- os conceitos-chave e a lógica interna do texto designam, em primeiro lugar, a variedade de sentidos que podem ser atribuídos a um determinado conceito-chave. Devido à diacronia, os termos e conceitos são ressignificados e os sentidos podem migrar. Assim, um termo pode ser significado de uma forma em determinado contexto histórico, porém em outras conjunturas, ele adquire um novo sentido. Em segundo lugar, é fundamental analisar a lógica interna de um texto, seus esquemas explicativos e a textura dos argumentos.

Tais critérios descritos e fundamentados por Cellard (2008) foram observados e aplicados na pesquisa bibliográfica e coleta de dados, ${ }^{7}$ objetivando construir um estado da arte de G. H. Mead atendo-se aos pormenores da investigação científica.

\title{
20 efeito redoma e o descaso histórico
}

\begin{abstract}
Às vezes, o espanto pode provocar a lucidez. A existência de autores que desenvolveram análises psicológicas de fôlego, entre outros os acima nomeados [Lev Vygotsky, George Herbert Mead e Henri Wallon], e que permanecem nos escaninhos da academia, evidenciam o desprezo dos psicólogos, não pelo 'antigo', pelo 'démodé' ou, se preferir, pelo 'clássico', mas, lamentavelmente pela história da ciência que juram produzir (SASS, 2004, p. 22).
\end{abstract}

\footnotetext{
${ }^{7}$ A partir desse trecho elaboro uma distinção entre pesquisa bibliográfica e coleta de dados. Pelo termo pesquisa bibliográfica entendemos o mapeamento de autores, de fontes filosóficas e científicas que contribuíram na formulação do pensamento meadiano, e por coleta de dados as notas de alunos que assistiram o Curso Anual de Psicologia Social de G. H. Mead, na Universidade de Chicago.
}

Cad. de Pesq. Interdisc. em Ci-s. Hum-s. Florianópolis, Santa Catarina, Brasil, ISSN 1984-8951 v.14, n.105, p.19-49 ago/dez 2013 
Aqui vamos partir da fons et origo para depois detectar o descaso histórico com Mead nos Estados Unidos e, na medida do possível, no contexto brasileiro. De acordo com Marková (1982), os trajetos diacrônicos tomados pelas historiografias da filosofia ocidental são geralmente produto de um embate, uma incongruência implícita entre o racionalismo e o empirismo. Tais construções históricas obscurecem o tronco comum dessas filosofias que, ao fundo, são de inspiração cartesiana. O conflito verossímil não está entre Hume e Descartes ou entre John Locke e Descartes, mas, sim, entre René Descartes e Georg Wilhelm Friedrich Hegel. Este mais conhecido pelo último nome. $O$ desacordo deve ser angariado ao leste da França, na Alemanha, e não ao norte, no Reino Unido - esperamos deixar claro que referimo-nos aos aspectos morfológicos e não aos geográficos.

No escopo de Kuhn (1998), o advento do descaso corresponde à incompatibilidade de paradigmas. A ciência normal, ou melhor, o paradigma reúne dois fundamentos cruciais: a falta de precedentes nas realizações servindo para recrutar membros partidários, compondo um grupo duradouro que se estende no tempo e espaço. Ao mesmo tempo, as realizações não podem ser um universo fechado em si mesmo, afinal deveria haver certo parâmetro de abertura suficiente para permitir toda a espécie de problemas a serem deslindados. Quem deveria tomar para si esse encargo? No ponto de vista de Kuhn, é o grupo indefinido de praticantes daquele paradigma considerado. Na concepção de Marková (1982), o emprego de paradigma remete não para um sistema científico, mas sim para um sistema de pensamento em filosofia. O uso efetivado pela autora é totalmente válido e contribui na explicação porque, no devir de séculos, algumas maneiras de pensar, certos apriorismos de pensamento estão incrustados e enviesam o próprio medrar da pesquisa, e vão além dela, sem ser plenamente reconhecidos pelo filósofo e/ou cientista (FARR, 1996).

Nos cenários da Universidade de Chicago, a relação especificada por Marková ganha corpo, em 1900. Nesse ano, John Broadus Watson inscreveu-se no doutoramento, com supervisão de John Dewey, contudo, no frigir dos ovos, acabou por completar seus estudos, sob orientação de Angell. Mead foi para Chicago, em 1894, acompanhado de Dewey e, como já foi mencionado nas páginas anteriores, começou a ministrar seu curso de psicologia social, em 1900. Portanto, é razoável afirmar que Watson foi aluno de Mead no primeiro ano em que o curso fora 
proferido. Em meados de 1912 até 1915, Watson preside a American Psychological Association. Quatro anos antes, em 1908, já havia deixado Chicago rumo a Johns Hopkins, para assumir o cargo de docente. Em 1904, quando Dewey troca Chicago pela a Universidade de Columbia, os psicólogos encabeçados pelo até então orientador nos estudos de Watson, Angell, criam um departamento próprio, independente da Faculdade de Filosofia, e deixaram de recomendar o curso organizado por Mead (SOUZA, 2006). Watson, quando ainda era presidente da American Psychological Association, elaborou um manifesto behaviorista cujo objetivo principal era desprover as noções de self, consciência e mente da psicologia. Esses são os conceitos basilares defendidos por Mead. "Os psicólogos seguiram Watson, do mesmo modo como os habitantes de Hamelin seguiram o tocador de flauta" (FARR, 1996, p. 88). Esse encadeamento quase alheio de episódios transparece seguir uma mesma direção, isto é, Watson pretendia exorcizar o fantasma de Descartes por meio de um método objetivo de análise do comportamento. Ao fazê-lo, tenta limpar o campo psicológico de toda e qualquer referência à mente, ao self ou à consciência. Os seguidores do tocador de Hamelin do watsonismo - estavam convictos de que a filosofia cartesiana já não pairava no mesmo ar que respiravam. Mead (2010) frisa que Watson agiu de maneira similar a Rainha de Alice no País das Maravilhas - "Cortem as cabeças!", pois não existem imagens na memória e muito menos consciência.

O paradigma cartesiano continua a existir no behaviorismo indiscriminadamente, sem ser percebido. A empresa vã de Watson pressupunha que, ao focar naquilo que se objetivamente vê, tornando a psicologia uma ciência do comportamento, havia se livrado do racionalismo de Descartes. Pelo contrário, o behaviorismo não foi além dos dualismos cartesianos, inclusive o mais central deles entre mente e matéria (MATOS, 1995). Os psicólogos de Chicago pensaram ir além da filosofia mental do self em Wundt e a introspecção ao adentrar numa fase científica da disciplina, todavia ambas as vertentes, wundtiana e behaviorista, pertencem a um mesmo e único paradigma: o cartesiano. Tal como uma moeda, em que, de um lado tem-se empirismo, mais próximo do behaviorismo metodológico em Watson, e, na outra face, o racionalismo, afigurado na percepção dos processos internos e no mentalismo em Wundt (FARR, 1996). 
O hiato entre Mead e Watson é mais bem equacionado na própria definição meadiana sobre o behaviorismo. Para Mead (2010), o átrio epistêmico de entrada da ciência comportamental do outro é a psicologia animal. O outro, por sua vez, é compreendido na lente de Meyer (1921 apud FARR, 1996) como um objeto físico, uma planta, um instrumento mecânico ou até mesmo outro ser humano. $\mathrm{O}$ advento dos primeiros estudos na psicologia animal obteve algum conhecimento com inferência a consciência e chegou ao ponto de mensurar a partir de que momento a consciência manifesta-se na conduta. Entretanto, essa proposição não podia ser levada adiante, porque não pôde ser testada em experimentos específicos. Então, a solução adotada para o revés foi descartar a hipótese. A posição behaviorista mostrou-se disposta a transpor a sua concepção dos animais inferiores para o animal humano (MEAD, 2010). Eis aqui uma forte disparidade entre Mead e Watson, o último foca na continuidade e o primeiro na descontinuidade inerente entre os animais inferiores e os seres humanos. Mead interessa-se pelo mecanismo de complexificação na linguagem humana, e em que medida isso influi na filogênese, a evolução da espécie e na ontogênese, na evolução de cada membro individual considerado.

O manancial da divergência entre os autores parece vir de antes, no paradigma em que inscreveram as suas teorias. Pelos apontamentos de Marková (1982) e Farr (1996), poder-se-ia asseverar pela seguinte linha de raciocínio: se Watson deixou-se enganar pela sua própria volição e ao invés de exorcizar o fantasma de Descartes o desenterra, em que campo situa-se Mead? Seria ele um herdeiro da tradição filosófica de Wundt? Ou seja, ainda está inscrito no mesmo paradigma cartesiano de Watson? A compreensão de Farr quanto a isso é seminal e, a nosso ver, constitui uma das maiores contribuições em historiografia da ciência psicológica. Aliás, tanto Farr como Joas (1985), um na Inglaterra e outro na Alemanha, são, até o fim da primeira década do século XXI, as duas melhores interpretações do pensamento de Mead. Vale enfatizar, são impulsos exegéticos europeus e não americanos. ${ }^{8}$ Souza (2006, p. 22), em nota de rodapé de sua dissertação, salienta um apanágio análogo em relação à Farr através destes dizeres: "Interessante refletirmos, um inglês, Robert Farr, discutindo a psicologia americana,

\footnotetext{
${ }^{8}$ Apesar de isso não ter sido mencionado até o presente momento na nossa estratégia textual, George Herbert Mead é americano, nasceu em South Hadley, Massachutsetts, em 1863 (SOUZA, 2011).

Cad. de Pesq. Interdisc. em Ci-s. Hum-s. Florianópolis, Santa Catarina, Brasil, ISSN 1984-8951 v.14, n.105, p.19-49 ago/dez 2013
} 
citando autores compatriotas de Mead, e que não o destacam como sujeito de importância para a história da Psicologia Social".

A resposta que Farr (1996) formula às questões levantadas no parágrafo anterior é que Mead pertencia a um paradigma, no emprego corrente de Marková, um sistema em filosofia que é incompatível ao de Descartes, isto é, o paradigma hegeliano. Nesse sentido, a filosofia hegeliana apresenta maiores conformidades com a psicologia de Mead, visto que ela é mais explicitamente social que aquela de Descartes. Ao invés de dicotomias cartesianas entre mente e corpo, sujeito cognoscente e objeto cognoscível, tem-se o self em relação ao outro. São mais relações "e/ambos" e menos dualismos "ou/ou". A filiação de Mead a Hegel é o ponto de ruptura com o tipo de psicologia social desenvolvida no âmbito norteamericano. Essa última floresceu e se desenvolveu historicamente dentro do paradigma cartesiano. Por isso, no inicio dessa seção, Sass (2004) aponta três nomes apagados nos manuais de psicologia, a saber: Henri Wallon, Lev Vygotsky e George Herbert Mead. Precisamente, esses três teóricos estão enraizados no solo do paradigma hegeliano. Se o desenvolvimento histórico da psicologia social estadunidense surge no interior da filosofia cartesiana, é fácil menosprezar a importância e originalidade da teoria psicossocial de Mead, que, por seu turno, finca raízes em Hegel.

Vamos nos estender um pouco mais nos escólios desse tema, afinal é o germe do descaso histórico de Mead, em maior grau na psicologia e em menor proporção na sociologia. O behaviorismo de Watson, e de toda sorte de psicólogos que o seguiram, rechaçara profundamente os filósofos, ao ver neles um pecúlio resultante da reflexão de séculos. Contudo, esse produto do pensamento filosófico não poderia ser levado a sério, pois tinha origem nos gabinetes. Os filósofos, na perspectiva dos psicólogos behavioristas, estavam confortavelmente sentados em suas poltronas e já passava da hora de desenvolver uma ciência comportamental do outro. Meyer (1921 apud FARR, 1996) é um exemplo elucidativo, porque faz um chamado estridente aos psicólogos, dizendo para abandonarem a metafísica e encetar a busca do futuro científico. Pensamos que a partir do que já foi dito, sobretudo nesse trecho, torna-se evidente que behaviorismo é a forma de positivismo dentro da psicologia (FARR, 1996). Na "Introdução", trouxemos alguns elementos que já apontavam a tendência para essa apropriação, mormente quando 
Allport (1954) designa Comte como o fundador da psicologia social. Na Universidade de Chicago, a criação do Departamento de Psicologia, em 1904, por incentivo de Angell, e as cadeiras vazias deixadas pelo abandono dos psicólogos ao curso de Mead são os indícios reais da situação em que o positivismo entra pela porta dos fundos da psicologia, vai recrudescendo até o ponto que essa se fecha à longa história tecida pela reflexão filosófica. É óbvio que não se pode sintetizar o estado do descaso histórico somente tomando como cerne da análise o processo descrito; a indiferença científica advém da incompatibilidade de paradigmas.

No que tange à incompatibilidade, arriscamo-nos a intitular as ilações daquela pela expressão "efeito redoma". Pelo prisma de Kuhn (1998), o aluno é preparado para integrar uma determinada comunidade científica, na medida em que estuda os paradigmas. Se ele é um estudante de física, deverá possuir algum conhecimento de causa sobre a Dinâmica Aristotélica, a Óptica Corpuscular, a Astronomia Ptolomaica e assim por diante. Mais tarde, quando ingressar na comunidade científica, encontrará ali pessoas que apreenderam os mesmos modelos concretos, originários de campos basilares de estudo. Em virtude disso, a prática científica desse estudante provavelmente não criará desacordos e antagonismos inauditos. Marková (1982) colmataria a questão pelos vincos deixados no saber fazer científico pelo sistema filosófico. Assim, a comunidade de psicólogos sociais nos Estados Unidos poucas vezes endereça as amarras canônicas da disciplina em Mead, porque no âmbito do ensino nas universidades, decerto, ocorre a preservação das teorias, dos modelos explicativos e dos teoremas fundamentados em uma matriz filosófica cartesiana. Por esse motivo, o efeito daquele aprendizado é manter os egressos do campo presos numa redoma de vidro. Essa analogia é estratégica, tendo em vista que concilia duas atividades contraditórias, alguma dose de aprisionamento científico, na maioria das vezes inconsciente, e a possibilidade de consciência dos limites latentes ao próprio paradigma, no qual o especialista efetua a sua ciência. Por isso que nossa redoma é transparente, por vezes, translúcida ou totalmente opaca.

Por outras palavras, o substrato de bases teóricas comuns serve para vincular os especialistas uns aos outros, estabelecendo assim a comunidade científica de Kuhn. Assim, reconhecer a grade epistêmica que repousa a formação de egressos é um passo, no entanto, cabe ainda elucidar como essas relações históricas objetivas 
são conjugadas no seio dos corpos individuais. Falar que os discípulos aprenderam com os mestres do campo científico é um argumento mais ou menos tacanho, porque atribui toda culpa em uns e exonera outros. Uma saída razoável é nos ancorar na ideia escolástica de habitus em Bourdieu (1994). Se o habitus é produto da história e produz práticas, sejam elas individuais ou coletivas, ele também produz a história, em conformidade com os esquemas engendrados historicamente. Desse modo, um desdobramento patente na assertiva é que o habitus assegura a presença das experiências e aprendizados passados que tendem a conformar as práticas no presente, e garantir os ditames de regularidade e continuidade a elas. A máxima de Bourdieu sumariza o dito: "um sistema de disposições duráveis, de estruturas estruturadas predispostas a funcionarem como estruturas estruturantes [...] objetivamente adaptadas a seu fim sem supor a intenção consciente dos fins" (BOURDIEU, 1994, p. 61). O grau de impregnação do habitus nos agentes determina e esvaece a medida da intenção consciente dos seus próprios fins. Nos laivos positivistas da psicologia americana, o efeito redoma é a consequência direta do habitus nos egressos e iniciados, e a variante metafórica do seu cariz (transparente, translúcido e opaco) varia em consonância com o grau de inculcação do habitus.

O ônus da prova da possibilidade de cariz opaco na redoma tem expressão empírica em Skinner. No livro "Verbal Behavior", Skinner (1957) discursa sobre o comportamento expressivo, porém o faz sem nenhuma referência a Mead, sendo que a psicologia social meadiana tem vastas menções acerca da linguagem. Dessa maneira, devemos nos ater a um uso cuidadoso e circunspecto da significação da ideia defendida, ou seja, o efeito redoma, no tocante à pertença do mentalismo e behaviorismo a um mesmo paradigma, não é uma armadilha em que se cai de uma vez por todas, sem alternativa de saída. Não é um atavismo epistemológico sem fim. O atestado para ratificar essa proposição pode ser logrado em Mead, que percebeu isso em 1920 e procurou resolver o problema (FARR, 1996). Além disso, o fenômeno adquire proporções ampliadas e não está restrito apenas à tradição estadunidense em história da psicologia, mas, também, se verificam vestígios dele no desenvolvimento histórico da psicologia social no contexto brasileiro. 
Souza (2006, p. 6) nos mostra que o status quo da teoria de Mead, no Brasil, não era tão diferente daquele constatado na América do Norte e, em certo sentido, até pior:

Desde a procura pelas bibliografias indicadas para o exame de
conhecimentos, e posteriormente ao querer me aprofundar nos estudos
meadianos para a construção do projeto [de pesquisa para o ingresso no
Programa de Estudos Pós-graduados em Psicologia Social na PUC - SP],
estranhava não encontrar livros do Mead em livrarias e sebos; em
bibliotecas eram antigos, poucos e raros, os volumes em espanhol ou
inglês.

No processo de investigação, Souza partiu de algumas contingências históricas que precipitavam na negligência de Mead, e logo percebeu que aquelas eram intensificadas e corroboravam no descaso, a medida que eram desveladas nos meios clássicos de divulgação da ciência psicológica: os livros e manuais. O universo examinado por Souza é relativamente pequeno, mas contribuiu na identificação de omissões significativas nas bibliografias. O autor esquadrinhou livros e manuais na biblioteca da Pontifícia Universidade Católica de São Paulo, fazendo o uso de determinadas expressões-chave nos terminais informatizados, tais como "História da Psicologia Social", "Manual de Psicologia", etc. Do resultado da mensuração, Souza levantou 28 obras. Dessas, cinco citavam o nome de Mead uma única vez, seja através de referências, citação ou rodapé. Outras quatro obras faziam menção ao filósofo norte-americano mais vezes e dedicavam maior espaço para expor seus contributos. Entretanto, o cálculo inverso desvela o total de 19 obras, que se silenciaram sobre a existência e o préstimo de Mead para a psicologia.

O paradoxo interessante é que Souza efetiva sua análise num espólio paulistano e foi certamente na cidade de São Paulo que Mead ganhou expressão pela primeira vez no Brasil. Em meados de 1940, o sociólogo estadunidense Donald Pierson ministrou, na Escola Livre de Sociologia e Política da Universidade de São Paulo, um curso de psicologia social (MENDOZA, 2005). Bomfim (2004) debruçouse na pesquisa histórica sobre o início dos cursos de psicologia social no Brasil, e colocou em relevo a presença de Pierson na USP (Universidade de São Paulo). Robert Park (1864-1944), docente na Universidade de Chicago, foi aluno do curso de psicologia social de Mead e, além do mais, orientou Pierson. Decerto, as linhas 
de influência são de Mead a Pierson, através de Park. Becker (1996) endossa a inferência de Bonfim, visto que na sua última visita ao Brasil, no outono de 1990, pronunciou uma conferência para o Programa de Pós-graduação em Antropologia Social da UFRJ (Universidade Federal do Rio de Janeiro), tendo como eixo temático a Escola Sociológica de Chicago. Na sua alusão aos expoentes dessa escola de atividade $^{9}$ que aportaram na sociologia brasileira ${ }^{10}$ destaca o nome de Pierson. Conforme verificaremos adiante, a tarefa de difusão da teoria meadiana tanto na América do Norte como no Brasil foi desempenhada, geralmente, por sociólogos vinculados à orientação da Escola de Chicago. Todavia, o Brasil, bem como vizinhos latino-americanos, tem uma particularidade no que tange às línguas.

Isto posto, a língua dominante na disseminação da psicologia social americana naturalmente é o inglês. Em parte, a dominância que certas escolas intelectuais estadunidenses têm pelo mundo afora se deve às características da língua inglesa. Trata-se de uma língua falada globalmente na ciência (FARR, 2007). Portanto, no caso da América do Sul, a negligência na difusão de Mead tem origem ainda em certa marginalidade das línguas latinas e nas políticas editoriais adotadas. O espanto de Souza em 2006, quanto à inexistência de traduções em língua portuguesa do clássico "Mente, Self e Sociedade", editado por Morris, seria abrandado pela publicação da mesma obra em português, no ano de 2010, pela editora brasileira Idéias \& Letras. O nosso levantamento bibliográfico indica uma

\footnotetext{
${ }^{9}$ Becker (1996) cita Samuel Guillemard, um graduado da Northwestern University, por elaborar uma diferença conceitual entre escola de atividade e escola de pensamento. A escola de pensamento, na conceituação de Guillemard, consiste em um grupo de indivíduos que tem em comum o fato de outras pessoas considerarem seu pensamento semelhante, frequentemente muitos anos mais tarde, decidese que esses teóricos estavam fazendo a mesma coisa e pensando de maneira similar. A escola de atividade, por sua vez, designa um grupo de teóricos que trabalham em conjunto, não sendo fundamental que os integrantes da escola de atividade compartilhem da mesma teoria. Esses teóricos, autores e pensadores devem apenas estar dispostos a trabalharem juntos, assim como ocorreu na Escola Sociológica de Chicago. Autores como Allbion Small e seu utilitarismo coletivo, Robert Park com sua concepção de ordem "ecológica" e George Herbert Mead e a sua elaboração de prerrogativas da psicologia social constituem o quadro teórico, o mosaico analítico da Escola de Chicago. As ideias elaboradas na Escola de Chicago apresentavam um compartilhamento pela maioria dos indivíduos, mas não por todos, não era necessário que todos concordassem com essas elaborações conceituais para engajarem de forma efetiva nas atividades que realizavam. Nesse sentido, a Escola de Chicago trata-se de um conjunto heterogêneo de reformistas sociais, pesquisadores e teóricos pertencentes à Universidade de Chicago que exerceram suas atividades de pesquisa empírica de 1890 a 1940. Becker ainda ressalta a Escola de Chicago como mais conhecida e reconhecida nos meios acadêmicos pela sua denominação do que pelo conteúdo e os avanços científicos, metodológicos e epistemológicos que efetivamente concretizou.

${ }_{10}$ Para Mendoza (2005), a sociologia da Escola de Chicago teve influência nas relações raciais; inclusive Pierson (1971) escreveu uma obra intitulada "Brancos e Pretos na Bahia: estudo de contato racial"; nas pesquisas acerca das comunidades, pequenas cidades rurais; e nos estudos da cidade.

Cad. de Pesq. Interdisc. em Ci-s. Hum-s. Florianópolis, Santa Catarina, Brasil, ISSN 1984-8951
} v.14, n.105, p.19-49 ago/dez 2013 
tendência paulatina de amenização do não reconhecimento teórico a Mead no contexto brasileiro. A esse respeito, salientamos a tradução do livro de Farr (1996), "As Raízes da Psicologia Social Moderna", a tese de doutoramento de Sass (2004), "Crítica da Razão Solitária: A Psicologia Social Segundo George Herbert Mead", publicada em formato de livro, a dissertação de Souza (2006), "George Herbert Mead: Contribuições para a Psicologia Social", além de uma série de artigos publicados em periódicos especializados, nomeadamente na área da psicologia social.

\section{G. H. Mead: considerações biográficas e a sua carreira}

George Herbert Mead era o segundo filho de Elisabeth Sorrs Billings com Hiram Mead, nasceu no inverno de 1863, mais precisamente no dia 27 de fevereiro, em South Hadley, Massachusetts, nos EUA. Hiram Mead era professor de homilética. Por algum atavismo, esperava-se que G. H. Mead seguisse a mesma carreira do pai na Faculdade de Oberlin. Entretanto, o filho encetou suas leituras na teoria da evolução de Darwin, logo desenvolveu sérias dúvidas da explicação cristã sobre o gênesis do mundo. A evolução em Darwin não era uma teoria escatológica, mas, sim, a prova irrefutável da natureza mitológica inscrita na doutrina cristã. Receoso das suas crescentes dúvidas, Mead prefere poupar a família de se inteirar de seu agnosticismo. A filosofia kantiana e o idealismo alemão contido nela acicatam o prospecto. Durante a graduação em 1883, na Faculdade de Oberlin, pouco depois da morte do pai em 1881, ele decide trabalhar para custear seus estudos universitários. Lecionou em uma escola secundária, devido a problemas disciplinares, encerra o seu vínculo empregatício e, em paralelo, conclui o primeiro degrau no ciclo universitário. Em meados da centúria, exerceu o ofício de agrimensor na Estrada de Ferro Central de Winconsin. A destreza e precisão técnica da profissão solidifica seu interesse pelas ciências naturais (JOAS, 1985, FARR, 1996, SOUZA, 2011).

Por um breve lapso de tempo, Mead levantou a hipótese de prosseguir na carreira de docente em filosofia nas escolas, apesar da sua desastrosa experiência de outrora. Ele tinha noção do controle clerical no interior das instituições de ensino e pesquisa, e estava cônscio que teria de exercer um magistério secularmente 
doutrinário - perdoa-nos o oximoro. Em 1887, a conselho de seu amigo Henry Castle, matriculou-se no mestrado em filosofia e psicologia na Universidade de Harvard. A opção institucional de Mead longe de ser aleatória e afetiva, alicerça-se na racionalidade. Harvard estava próxima da Johns Hopkins University, creditada na época como a melhor universidade gratuita em solo americano. Os anos em Harvard foram frutíferos e rendeu significativos contatos intelectuais para Mead. $O$ jovem de South Hadley conheceu a interpretação do professor neocristão-hegeliano Josiah Royce sobre Kant, e pode discernir daquele esquema apreendido em Oberlin, no momento de sua graduação. No interim em que se manteve afastado dos bancos da academia, Mead destinou o tempo vago para leituras mais profundas em Kant. Em decorrência, toma-o como a via basilar para reivindicar o postulado da liberdade moral e, concomitantemente, combater o dogma teológico. Foi também em Harvard que ele tornou-se tutor dos filhos de James, para quem Mead redigiu um trabalho. James se mostrou impressionado e ao decurso de meses, ambos travaram prodigiosos debates (SOUZA, 2006, JOAS, 1985).

Castle, após a estada em Harvard cursando Direito, decidiu-se pelo estudo da Filosofia em diversas universidades na Alemanha. Em vista do ensejo, Mead foi para Leipzig, lá se inscreveu nas aulas com Wundt sobre a psicologia científica estrutural e revisou os primeiros volumes da Völkerpsychologie de Wundt. Em 1889, se dirige a Berlim entabulando suas pesquisas da tese de doutoramento com a orientação de Dilthey. $\mathrm{Na}$ investigação do doutorado, Mead tinha em mente superar o pendor fenomenalista em Kant. Por exemplo, Kant entende o espaço como uma forma de intuição, no entanto, o espaço em Mead corresponde a uma reverberação construcional da cooperação entre a visão e o tato. Assim, Mead é muito mais um filósofo dos sentidos do que um fenomenalista (FARR, 1996, SOUZA, 2011).

Em sua estadia na Alemanha, Mead teve contato com a antítese de Wundt, os preceitos filosóficos de Dilthey e Heider, a educação em Paulson, o idealismo alemão de Hegel, a psicologia fisiológica e experimental de Ebbinghaus, além de ter tido uma profunda compreensão da teoria da evolução de Darwin. ${ }^{11}$ Mesmo após seu retorno aos Estados Unidos, em 1891, manteve-se inteirado dos desdobramentos teóricos e filosóficos da Europa. (JOAS, 1985, SANT'ANA, 2005;

\footnotetext{
${ }^{11}$ Mead (2010) analisou um artigo de Darwin publicado em 1872, The Expression of the Emotions in Man and Animals, e compreendeu-o como uma profunda e detalhada abordagem em psicologia comparativa.

Cad. de Pesq. Interdisc. em Ci-s. Hum-s. Florianópolis, Santa Catarina, Brasil, ISSN 1984-8951 v.14, n.105, p.19-49 ago/dez 2013
} 
SOUZA, 2006). Por isso, Mead é uma personagem particularmente importante no desenvolvimento da psicologia social, na Universidade de Chicago. Ele foi, fundamentalmente, o aporte europeu, as raízes no velho mundo, a ponta da lança nos Estados Unidos e na Europa.

Antes de partir da Alemanha, Mead casou-se com a irmã do amigo Castle, que havia falecido num acidente de navio no começo de 1891. O motivo do regresso de Mead era assumir um cargo de instrutor de filosofia e psicologia em Michigan, a convite de Dewey. A perspectiva de futuro na docência, obrigara-o a deixar Berlim, precipitadamente, abandonando dessa maneira o doutorado. Já em Michigan, encontrou C. H. Cooley, que o introduziu nos escritos econômicos de Adam Smith. Domingues (2001) ressalta que o conceito "eu espelho" de Cooley contribuiu particularmente para o desenvolvimento das premissas da psicologia social de Mead. Esse conceito refere-se às interpretações que "eu" tenho a partir das percepções e interpretações que os outros elaboraram e elaboram sobre "mim". Do pensamento liberal de Adam Smith, Mead auferiu a noção de "assumir o papel do outro". No fluxo contínuo de transações do mercado, vendedores e compradores interagem comercialmente, assumindo os papéis uns dos outros e, ao fazê-lo, estimulam a eficiência dos mercados. Não obstante, ao medrar a coerência interna e encadeamento articulado entre os conceitos, Mead retificou e substituiu a noção de "assumir o papel do outro" pela de "adotar a perspectiva do outro". A nova noção advém da leitura de Einstein. A perspectiva é um ponto situado objetivamente no tempo e no espaço, do qual os eventos são percebidos (MEAD, 1927 apud FARR, 1996).

Esses horizontes científicos e filosóficos ilustram o panorama conceitual de Mead. Domingues (2001) destaca que o psicólogo social caracterizou a mente segundo três aspectos fundamentais: a utilização da linguagem simbólica, sobretudo, os gestos e palavras; o uso de "gestos convencionais" e a capacidade de realizar "ensaios de interação". Mead caracteriza a mente não como algo dado, mas como um processo. A mente, nesse sentido, não existe de forma isolada, mas imbricada com o corpo e constantemente submetida ao processo interativo. $O$ autor especifica o pensamento meadiano, referindo-se ao conceito de sujeito (self). Esse é caracterizado enquanto simultâneo e ativo do sujeito, o ator social faz-se objeto de si mesmo e da sociedade, compondo-se de dois traços elementares: o "eu" e o "mim". 
O "eu" é ativo do sujeito precedente ao processo reflexivo no que se refere à ação social, ao passo que o "mim" é posterior e já condicionado da percepção que os outros têm do ator, sendo altamente reflexivo. Segundo Domingues (2001), a importância capital de Mead também reside nas etapas básicas do interagir, apreendido pelo sujeito no fluxo de sua socialização, de sua interação com a vida social, sendo constituídas por três fases. A "brincadeira" como modelo de ação social, sujeita ao mínimo de empecilhos para sua concretização, caracteriza-se pela sua espontaneidade. No "jogo", há regras claras de interação e são definidos os papéis que se devem cumprir. "O outro generalizado", por sua vez, "o indivíduo teria acesso a todos os papéis de sua comunidade sendo capaz de se ver nele e compreender [...] respondendo adequadamente no curso da ação" (DOMINGUES, 2001, p. 27).

No final do século XIX, na recém-fundada Universidade de Chicago, Dewey assume a cátedra fundacional de pedagogia, trazendo com ele Mead para assumir o cargo de professor assistente. Após seis anos enquanto professor em Chicago, em 1900, Mead começou a ministrar o seu Curso Anual de Psicologia Social, que era vinculado ao Departamento de Filosofia e Psicologia. Naturalmente, tanto os psicólogos quanto os filósofos frequentavam as aulas. Isto até 1904, quando Dewey vai para Columbia, e os psicólogos criam um departamento desmembrado da Faculdade de Filosofia. Na seção "O Efeito Redoma e o Descaso Histórico", já relatamos a tessitura do acontecimento e quais suas consequências. No frigir dos ovos, os discentes da pós-graduação em sociologia, por recomendação de Allbion Small, comparecem as aulas de Mead. Diversas gerações de sociólogos foram influenciadas pela psicologia social em Chicago, principalmente a partir de 1920 até 1931, último ano do curso, devido as recomendações insistentes de Faris (LEWIS; SMITH, 1980), e por essas e outras que Mead aparece como figura eminente na Escola Sociológica de Chicago.

Joas (1999) descreve a Escola de Chicago como a combinação de uma orientação política fortemente reformista, orientada para as potencialidades da democracia, em um cenário de intensa urbanização e industrialização, de uma filosofia pragmática da ação ${ }^{12}$ e de esforços urdidos, para transformar a sociologia

\footnotetext{
12 Joas salienta que o pragmatismo é uma filosofia da ação e desenvolveu o conceito de ação a fim de superar os dualismos cartesianos, colocar em dúvida a dúvida cartesiana. O pragmatismo foi uma fonte filosófica do interacionismo simbólico e da Escola Sociológica de Chicago, assim busca ideias Cad. de Pesq. Interdisc. em Ci-s. Hum-s. Florianópolis, Santa Catarina, Brasil, ISSN 1984-8951
} v.14, n.105, p.19-49 ago/dez 2013 
em uma ciência empírica sem solapar a imensa relevância das fontes pré-científicas do conhecimento empírico. Joas (1999) salienta que uma interpretação minuciosa da obra e do conteúdo teórico de pensamento da Escola Sociológica de Chicago requer do pesquisador extirpar certos equívocos, tais como: a Escola adotava uma orientação ou percurso exclusivamente experimental e considerava as pesquisas como meras emanações dos objetos investigados; segundo, a Escola estava interessada somente em promover e divulgar reformas sociais; um terceiro equívoco refere-se em considerar a Escola de Chicago como resultado, produto e reverberação do estudo das obras de pensadores clássicos europeus, também como da apropriação de suas elaborações teóricas.

A Escola de Chicago não produziu tratados teóricos, mas confeccionou quase sempre um quadro mosaico de estudos semi-etnográficos. Porém, esse aspecto não pode fornecer a falsa percepção de que a produção científica de seus membros não partilhasse, endogenamente, pelo menos de uma mesma matriz teórica e de certos pressupostos metodológicos comuns. "Ainda assim um quadro teórico geral e implícito do pragmatismo - que, no entanto jamais recebeu bases metateóricas explícitas - pode ser observado nos sólidos teoremas individuais da Escola" (JOAS, 1999 , p. 143). Essas tais bases metateóricas referem-se ao processo de desenvolvimento de teorias empiricamente sustentáveis para áreas específicas da diversidade fenomênica.

Nesse sentido, a influência de Mead entre os sociólogos perdura, mesmo após a sua morte, em 1931. Prova disso é a difusão da psicologia social no Brasil, em 1940, por um sociólogo, Pierson (BOMFIM, 2004). Aliás, o falecimento de Mead foi tudo menos um evento plácido e brando. Refiro-me a uma disputa entre Mead e Hutchins, o Reitor da Universidade de Chicago, e não a enfermidade que culminou na morte do nosso filósofo e psicólogo social. Joas (1985) depois de ter lido um sumário dos espólios de Miller (1973) cujo teor continha pormenores detalhados, circunspectamente, narra-nos: a causa do descontentamento de Mead era indicação de Mortimer Adler para ser docente em Chicago, feita pelo Reitor, sem avaliar as vontades do departamento e do seu chefe, cargo ocupado por Mead na época. Joas

relevantes para explicar a ação social se diferenciando profundamente da noção utilitarista do agente solitário. Para maiores detalhes ver: JOAS, Hans. Interacionismo Simbólico. In: GIDDENS, A.; TURNER, J. Teoria Social Hoje. São Paulo: Editora UNESP, 1999, p. 127-174. 
explica que Hutchins e Adler eram pessoas insignes para os emigrantes provenientes do Terceiro Reich, para quem a Universidade de Chicago se converteu num lugar de encontro. Tais casos contrastavam com os princípios e tradições da instituição conservados por décadas. Nesse mesmo período, Mead já doente recebeu a visita de Dewey que o convence a deixar Chicago e ir para a Universidade de Columbia em 1931. Mead não assumiu o cargo em Nova lorque, faleceu antes que pudesse ocupá-lo (MILLER, 1973, FARR, 1996).

\section{Entre o autor e o editor: a sobreinterpretação das ideias de Mead}

O que tentaremos acentuar adiante extrapola o campo da psicologia apesar de estar intimamente ligado a ela, tem haver com a filosofia do conhecimento e, em certa medida, com a semiótica. Na natureza de uma tentativa, pedimos para considerarem as inflexões como ensaios de inferências ou, quem sabe, no sentido popperiano de formular as proposições e submetê-las a um critério de falseabilidade (POPPER, 1972). Assim, Eco (1993, p. 59), professor titular de Semiótica na Universidade de Bolonha - Itália - reporta:

\footnotetext{
O debate clássico visava descobrir num texto ou o que o autor tencionara dizer ou o que o texto dizia independentemente das intenções do seu autor. Só após a aceitação do segundo termo do dilema podemos perguntar se o que é descoberto é o que o texto diz em virtude da sua coerência textual e de um sistema de significação original subjacente ou se são dos destinatários a descobri-lo na base do seu próprio sistema de expectativas.
}

Eco reconhece ao menos duas intenções sobre um texto qualquer, a intentio operis e intentio lectoris, e congrega uma ligação dialética entre elas. Por esse caminho, Eco é avesso ao debate clássico que prima por um ou por outro. Ele, ao contrário, esquadrinha dialeticamente aquilo que está no meio deles: o texto. O texto é um círculo hermenêutico, isto é, mais do que um mecanismo utilizado com intuito de validar a interpretação, o texto é um objeto construído pela interpretação no decurso do esforço circular de se validar "a si própria na base do que edifica como seu resultado" (ECO, 1993, p. 60). Portanto, um texto é um dispositivo concebido de tal forma que produz o seu próprio leitor modelo cuja principal iniciativa é idealizar, imaginar um autor modelo que, ao fim, acaba por confluir com a intentio operis. $\mathrm{O}$ leitor modelo em Eco não é aquele que faz uma única conjectura correta, contudo, o 
texto pode predizer certo leitor modelo habilitado a testar conjecturas infinitas. $O$ leitor real, ou empírico nos dizeres de Eco, constrói conjecturas sobre o tipo de leitor, modelo previamente postulado no texto. No terreno das convenções estilísticas, a estratégia textual pode apontar o leitor modelo. Por exemplo, uma construção frásica iniciada pela expressão "Era uma vez" é provável que seja um conto de fadas. Nesse caso, qual é o leitor modelo postulado pela intentio operis? Uma criança.

O autor modelo imaginado pelo leitor modelo não equivale ao autor empírico. Isto porque Eco é astuto e consegue perceber que a intenção intelectualmente manifesta de um dado ser humano é diferente da intenção linguística impressa na estratégia textual. Coexiste também um terceiro autor, um autor que está no limiar entre o autor modelo e o autor empírico. Para compreender o autor limiar, temos de nos mover para os bastidores da intentio operis, no processo de criação.

George Herbert Mead ensinou sem auxílio de apontamentos. Os textos que hoje possuímos sobre o curso de psicologia social foram estruturados a partir de notas de alunos e de um manuscrito estenográfico de 1927. De 1894 à 1931, Mead escreveu mais de 60 artigos, mas não chegou a redigir textualmente em uma única obra as suas ideias (SOUZA, 2006). Elas "conheciam um desenvolvimento interior rico demais para lhe permitir parar e anotar pensamentos, segundo um molde sistemático" (MORRIS, 2010, p. 10). Essas são palavras de Charles W. Morris, o editor do principal livro, elaborado com base naquele manuscrito de 1927 e nas notas dos alunos de Mead. Becker (1996, p. 183) adverte que a edição de Morris, a obra "Mente, Self e Sociedade", requer um empenho sobejado do leitor:

\footnotetext{
É preciso alertar a todos que desejam ler esse livro que ele é praticamente ilegível. Foi todo montado a partir de aulas proferidas por Mead porque seus alunos chegaram à conclusão de que ele jamais escreveria o livro. Alguém anotava o que ele dizia e foi desse modo que o livro foi preparado. Lê-lo é mais ou menos como ler um daqueles livros repletos de anotações e comentários feitos por outras pessoas.
}

A semiótica de Eco é fecunda para descortinar o fundamento da ilegibilidade, atribuída por Becker à edição de Morris. Saltam aos olhos ao menos três círculos hermenêuticos. Enfatizamos, "ao menos três", pode haver mais intentio operis, a saber são: a intenção do texto em "Mente, Self e Sociedade" e dos textos do qual a edição derivou, o manuscrito de 1927 e as notas dos alunos. Morris no prefácio não delimita quantos conjuntos de notas utilizou na edição, por isso "ao menos três" 
círculos hermenêuticos. Observe que não endereçamos nenhuma intentio operis tendo Mead como autor empírico, uma vez que o livro não foi diretamente redigido por ele. Cada intentio operis aporta-se num esforço circular: postula um leitor modelo, que imagina um autor modelo que, ao final, coincide com a própria intenção do texto. Na história da estratégia textual, o autor empírico de "Mente, Self e Sociedade" foi anteriormente leitor empírico do manuscrito e das notas, considerados separadamente. Ele fez pelo menos duas apostas interpretativas, duas conjecturas. No entanto, alguém pode questionar se Morris incluiu trechos de outras intenções linguísticas que não a sua em "Mente, Self e Sociedade", afinal o autor toma para si textos derivados para elaborar a sua edição. O argumento é mais ou menos inconsistente, haja vista que ao incorporar excertos de outras intentio operis e editá-los de acordo com a sua intenção intelectual de autor empírico, Morris criou uma nova intenção textual. A ilegibilidade da edição de Morris poderá residir na sobreinterpretação de suas conjecturas e/ou na distância relativa de Mead, em termos de criação do círculo hermenêutico. Note que, apesar de "Mente, Self e Sociedade" ter a psicologia social meadiana como predicado fundante, uma intentio operis do próprio Mead inexiste. Por fim, podemos inflexionar no que tange a um suposto autor limiar na edição.

Farr (1996) e Souza (2006) ressaltam que Morris era simpatizante de uma filosofia positivista da ciência, além de ter pertencido aos Novos Enciclopedistas e de ter almejado acentuar a unidade científica. Consequentemente, ele forneceu a designação "behaviorista social" para caracterizar Mead. Em vida, Mead nunca empregou o termo "behaviorista social", afinal era um severo crítico de Watson para se autonomear por meio dessa designação. Quiçá, as preferências filosóficas de Morris fluam no rio subterrâneo do inconsciente, fazendo brotar o autor limiar.

Acrescido a isso, Morris transparece não compreender bem a relação de Mead com Wundt. Ele esquece de mencionar o período de estudos de Mead na Universidade de Leipzig. Miller (1973), por sua vez, na obra George Herbert Mead: self, language and the world, afirma, de maneira equivocada, que Mead foi influenciado pela psicologia fisiológica de Wundt. A concepção de mente na ciência experimental de Wundt era de natureza cartesiana e, portanto, Mead foi crítico dela. O diálogo wundtiano de Mead dá-se, não na psicologia fisiológica, mas, sim, na Volkerpsychologie (FARR, 1996). Miller, assim como Morris, era um filósofo 
americano e editou uma outra obra a partir da transcrição de 1927, intitulada The Individual and the Social Self: unpublished work of George Herbert Mead (1982). Ambas as edições de Morris e Miller foram publicadas pela University of Chicago Press, porém em anos distintos - 1934 e 1972, respectivamente. Entretanto, Mind, Self and Society: from the standpoint of a social behaviorist de Morris é mais conhecida e serviu de veículo de divulgação da psicologia social meadiana mundo afora.

Existem pistas de que a edição brasileira do livro de Morris (2010) seja ligeiramente distinta da primeira versão publicada em 1934 e da edição argentina da Paidós de 1972, pois omite o subtítulo presente nas publicações anteriores: "from the standpoint of a social behaviorist" e "desde el punto de vista del conductismo social", respectivamente. Na edição da Idéias \& Letras é replicado apenas o título em português "Mente, Self e Sociedade". Para além das políticas editoriais, o prefácio de Morris lança luzes sobre o processo de revisão do manuscrito de 1927 e do material coligido de outros cursos de Mead, tais como os seminários sobre psicologia comparativa em 1912 e aqueles de consciência social, proferidos entre 1912 e 1920 (LEWIS; SMITH, 1980), além de um curso elementar de ética. É nesse contexto que Morris revela o nome de Herbert Blumer, que revisou partes da edição. $\mathrm{Na}$ circunstância, era mais do que natural que Blumer apresentasse sua arguição em torno de qualquer material que fosse publicado sobre as ideias de Mead, devido ao fato de ter assumido, em 1931, a série de palestras ministradas pelo filósofo e psicólogo social. Enquanto sociólogo, Blumer, seguindo os seus parceiros de departamento em Chicago, agiu considerando-se o herdeiro e guardião legítimo das proposições teóricas de Mead.

A intitulação da corrente interacionista simbólica foi cunhada pelo principal aluno de G. H. Mead, Herbert Blumer, em 1938 (BECKER, 1996). O aluno de Mead pertencia à mesma geração do antropólogo Redfield e do sociólogo Louis Wirth, e desenvolveu poucas pesquisas experimentais - era um teórico apesar de ter grande apreço pela pesquisa sociológica empírica. Aliás, a relação entre os constructos teóricos e a pesquisa experimental na sociologia se tornou um objeto de estudo de demasiado interesse por Blumer. Em sua tese de doutorado, The Method of Social Psychology (BLUMER, 1928 apud JOAS, 1999), estabeleceu as premissas fundamentais dos métodos da psicologia social. Para Joas (1999), Blumer converteu 
toda a processualidade da ação social em meros pilares dogmáticos do método. $\mathrm{O}$ autor delineia que, no interacionismo simbólico, Blumer se apega quase que exclusivamente aos problemas engendrados no conceito analítico de "ordem moral". Blumer se distingue ao elaborar tal conceito das tendências evolucionistas presentes no conceito de ordem "ecológica" de Park.

Lewis e Smith (1980), na análise dos fundamentos do interacionismo simbólico e da correlação dos membros da Escola de Chicago, concluem que Mead e o seu sucessor na Universidade de Chicago, Blumer, não pertenciam sequer ao mesmo campo metateórico. Se por um lado Mead era um realista mais próximo das vertentes filosóficas de Pierce, Blumer era um nominalista com fortes influências pragmáticas advindas de James e Dewey (PLUMMER, 2002).

$\mathrm{Na}$ perspectiva de Ritzer (1993), aquilo que Mead conceituava como ato social equivale a ação conjunta na abordagem de Blumer. A ação conjunta não reside na mensuração dos atos isolados individuais, tampouco possui uma natureza externa e coercitiva aos agentes. Por outro lado, insere-se no bojo de uma singularidade própria, donde os agentes empreendem suas ações. Deste modo, a vida em sociedade é produto do conjunto de indivíduos que atuam. Assim, a trama social humana consiste no emaranhado das ações realizadas pelos atores sociais. Diante disso, o conceito fundamental na teoria de Blumer que ilustra as suas apreciações das estruturas sociais é o Riot Image. Consiste no todo social apreendido por meio das ações, e estas essencialmente ligadas às ações dos grupos.

A leitura de Maines, citado por Ritzer (1993), sobre as reflexões sociológicas de Blumer, o conduziu à elaboração de três implicações no conceito de ação conjunta: a ação conjunta acarreta uma organização social a partir do momento em que a ação é efetivada de acordo com a sincronia dos padrões recorrentes; as ações se inclinam aos processos de institucionalização, pois são muitas vezes interligadas; a ação social não é anacrônica, possui continuidade, insere-se numa sucessão de acontecimentos históricos. A preocupação teórica de Blumer com as macroestruturas visualiza-se na organização, institucionalização e no lastro histórico das ações conjuntas.

A unidade básica da psicologia social de Mead, o ato comunicativo, foi bem compreendida por Blumer. Consabidamente, ele avaliou a real importância dos 
movimentos simbólicos de comunicação e da gesticulação expressiva para interpretar a interação social entre os seres humanos. Com mais expressão em 1920 (LEWIS; SMITH, 1980) do que antes, quando os sociólogos passaram a frequentar as palestras sobre psicologia social de Mead e o viram atacando o behaviorismo de Watson, provavelmente, devem ter suposto que Mead, tal como eles, era um antipositivista. Mas, o que Mead estava querendo dizer é que Watson não tinha avançado o suficiente, não havia alcançado uma explicação alicerçada em termos da história natural para as origens da mente e da autoconsciência. Mead era um darwinista e, em vista disso, tendia a compreender a emergência da mente como algo natural. Os sociólogos de Chicago e logo Blumer, por consequência, não estavam cientificamente propensos a entender a mente como um fenômeno natural e, menos ainda, a admitir as consequências evolucionistas da interação (FARR, 1996). Essas condições pavimentam os parâmetros da recepção científica, incitando apropriações sobreinterpretativas dos conceitos meadianos por parte dos sociólogos.

\section{Considerações finais}

No devir textual, enfatizamos dois movimentos inversos, mas complementares, num duplo esforço apreciativo paradoxalmente centrífugo e centrípeto. Ao buscar as causas do descaso histórico, vasculhamos aquilo que estava além da psicologia social de Mead, os antecedentes filosóficos e o plano das relações interpessoais e científicas de seu tempo. Ainda na leitura centrífuga, evidenciamos os desdobramentos epistemológicos da história da psicologia social, tendo por base a herança filosófica em Descartes. No enfoque centrípeto, asseveramos que, mesmo após algumas bibliografias atenuarem o isolamento teórico de Mead, certos impulsos de decodificação recorriam a conjecturas sobreinterpretativas, fomentando disformidades na compreensão de sua posição filosófica e científica. Assim, o remédio, ao invés de sanar a debilidade do corpo, volta-se contra ele.

Desde o Olimpo, algumas relações entre o mestre e os seus discípulos reverberam em tratados exegéticos de uns sobre outros. Por isso, no classicismo grego, a filosofia platônica é a égide da oralidade socrática. Reconhecendo os 
devidos limites da comparação e as disparidades conjunturais, Platão foi para Sócrates o que Morris e Miller foram para Mead. Entretanto, não sabemos até onde eles se equivocaram nas suas respectivas edições. Todavia, um percurso lógico para sinalizar o prospecto é aquele viabilizado por Eco. Poder-se-ia perquirir os 68 artigos publicados por Mead, proceder com apostas conjecturais e comparar com as conjecturas das intentio operis, equacionadas nas edições de Morris e Miller. Para verificar a validade das conjecturas, Eco (1993) sugere seguir o método de Agostinho: qualquer interpretação de dado excerto de um texto poderá ser aceita se for verificada por, e deverá ser descartada se for contrariada por, uma segunda parte do mesmo texto. Então, o pesquisador que enverede por esse rumo metodológico aquiescerá à uma dupla incumbência, recapitular os conceitos e descortinar eventuais tropeços iatrogênicos na literatura, resgatando assim os elos perdidos em Mead. 


\section{Referências}

ALLPORT, G. W. The historical background of modern social psychology. In:

LINDZEY, G. Handbook of Social Psychology. Reading: Addison-Wesley, 1954.

ARAÚJO. S. de F. Uma visão panorâmica da psicologia científica de Wilhelm Wundt. Scientiæ Zudia, São Paulo, v. 7, n. 2, p. 209-220. 2009.

BECKER, H. A Escola de Chicago. Mana, Rio de Janeiro, v. 2, n. 2, out. 1996.

BOMFIM, E. M. Históricos cursos de psicologia social no Brasil. Psicologia \& Sociedade, v. 16, n. 2. 2004.

BOURDIEU, P. Esboço da teoria da prática. In: ORTIZ, R. Pierre Bourdieu/Sociologia. São Paulo: Ática, 1994. p. 46-81.

BUTTERFIELD, H. The Whig Interpretation of History. Londres: Bell, 1951.

CELLARD, André. A análise documental. In: POUPART, J. et al. A pesquisa qualitativa: enfoques epistemológicos e metodológicos. Petrópolis: Editora Vozes, 2008. p. 295-316.

DOMINGUES, J. M. Teorias sociológicas no século XX. Rio de Janeiro: Civilização Brasileira, 2001.

DURKHEIM, E. As Regras do Método Sociológico. São Paulo: Cia Editora Nacional, 1976.

DURKHEIM, E. O Suicídio. Rio de Janeiro: Zahar, 1982.

DURKHEIM, E. A Divisão do Trabalho Social. São Paulo: Martins Fontes, 1977.

ECO, U. Sobreinterpretação de Textos. In: COLLINI, Stefan. Interpretação e Sobreinterpretação. Lisboa: Editorial Presença, 1993. p. 45-61. 
FARR, R. A Individualização da Psicologia Social. In: CAMPOS, R. H. de F. et al.

Paradigmas em Psicologia Social: a perspectiva latino-americana. Petrópolis:

Editora Vozes, 2007. p. 11-26.

FARR, R. A Psicologia Social na América Latina: futuros possíveis. In: CAMPOS, R. $\mathrm{H}$. de F. et al. Paradigmas em Psicologia Social: a perspectiva latino-americana. Petrópolis: Editora Vozes, 2007. p. 27-31.

JAHODA, G. Crossroads between Culture and Mind: Continuities and change in theories of human nature. London: Harvester/Wheatsheaf, 1992.

JOAS, H. G. H. Mead: a contemporary re-examination of his thought. Cambridge: Polity Press, 1985.

JOAS, H. Interacionismo Simbólico. In: GIDDENS, A.; TURNER, J. Teoria Social Hoje. São Paulo: Editora UNESP, 1999. p. 127-174.

KUHN, T. S. A Estrutura das Revoluções Científicas. São Paulo: Editora Perspectiva, 1998.

LEWIS, J. D.; SMITH, R. L. American Sociology and Pragmatism: Mead, Chicago sociology and symbolic interactionism. Chicago: University of Chicago Press, 1980.

MARKOVÁ, I. Paradigms, Thought and Language. Chichester: Wiley, 1982.

MATOS, M. Teorias de gênero ou teorias e gênero? Se e como os estudos de gênero e feministas se transformaram em um campo novo para as ciências. Estudos Feministas, Florianópolis, v. 16, n. 2. 2008.

MATOS, M. A. Behaviorismo Metodológico e Behaviorismo Radical. In: RANGÉ, B. Psicoterapia Comportamental e Cognitiva: Pesquisa, Prática, Aplicaçao e Problemas. Ed.Campinas: Editorial Psy, 1995.

MEAD, G. H. Espiritu, persona y sociedad: desde el punto de vista del conductismo social. Traducción Florial Mazia. 3. ed. Buenos Aires: Paidós, 1972. 
MENDOZA. E. S. G. Donald Pierson e a escola sociológica de Chicago no Brasil: os estudos urbanos na cidade de São Paulo (1935-1950). Sociologias, Porto Alegre, ano 7, n. 14, p. 440-470, jun./dez. 2005.

MILLER, D. L. G. H. Mead: Self, language, and the world. Austin: Texas, 1973.

MORRIS, C. W Mind, Self and Society: from the standpoint of a social behariorist. Chicago: University of Chicago Press, 1934.

MORRIS, C. W. Mente, Self e Sociedade. Trad. Maria Silvia Mourão. Aparecida: Idéias \& Letras, 2010.

PIERSON, D. Brancos e pretos na Bahia: estudo de contato racial. 2. ed. São Paulo: Companhia Editora Nacional, 1971.

PLUMMER, K. O interaccionismo simbólico no século XX: a emergência da teoria social empírica. In: TURNER, B. S. Teoria Social. Lisboa: Difel, 2002. p. 225254.

POPPER, K. R. A Lógica da Pesquisa Científica. São Paulo: Ed. Cultrix, 1972.

RITZER, G. Teoría Sociológica Contemporánea. Madrid: McGraw-Hill, 1993.

SAMELSON, F. History, origin myth and ideology: 'Discovery of social pychology'. Journal for the Theory of Social Behavior, v. 4, n. 2, p. 217-231. 1974.

SANT'ANA, R. B. Psicologia Social na Escola: as contribuições de G. H. Mead. Psicologia \& Sociedade, Porto Alegre, v. 17, n.1, p. 67-74, jan./abr. 2005.

SASS, O. Crítica da Razão Solitária: A Psicologia Social Segundo George Herbert Mead. Bragança Paulista: Editora Universitária São Francisco, 2004.

SKINNER, B. F. Verbal Behavior. Cambridge: B. F. Skinner Foundation, 1957.

SMITH, R. The History of the Human Sciences. London: Fontana, 1997. 
SOUZA, R. F. de. George Herbert Mead: contribuições para a psicologia social. 2006. 132 p. Dissertação. (Mestrado em Psicologia Social) - Programa de Estudos Pós-graduados em Psicologia Social, Pontifícia Universidade Católica de São Paulo, São Paulo, 2006.

SOUZA, R. F. George Herbert Mead: contribuições para a história da psicologia social. Psicologia \& Sociedade, v. 23, n. 2, p. 369-378. 2011.

WEBER, M. A objetividade do conhecimento nas Ciências Sociais. In: COHN, G. Max Weber/Sociologia. São Paulo: Ática, 2003.

Artigo:

Recebido em: 16/10/2013

Aceito em: $20 / 12 / 2013$ 